\title{
Methylene Blue and Brilliant Green Dyes Removal from Aqueous Solution Using Agricultural Wastes Activated Carbon
}

\author{
Ahmed Fate Ali ${ }^{1}$, Abdulsalami Sanni Kovo ${ }^{2}$, Sunday Adesola Adetunji ${ }^{2}$ \\ ${ }^{1}$ Department of Environmental Management, Bayero University Kano, Kano, Nigeria \\ ${ }^{2}$ Department of Chemical Engineering, Federal University of Technology, Minna, Nigeria \\ Email:Kovoabdulsalami@yahoo.com,kovo@futminna.edu.ng
}

How to cite this paper: Ali, A.F., Kovo, A.S. and Adetunji, S.A. (2017) Methylene Blue and Brilliant Green Dyes Removal from Aqueous Solution Using Agricultural Wastes Activated Carbon. Journal of Encapsulation and Adsorption Sciences, 7, 95-107.

https://doi.org/10.4236/jeas.2017.72007

Received: January 30, 2017

Accepted: June 25, 2017

Published: June 28, 2017

Copyright $\odot 2017$ by authors and Scientific Research Publishing Inc. This work is licensed under the Creative Commons Attribution International License (CC BY 4.0).

http://creativecommons.org/licenses/by/4.0/

(c) (i) Open Access

\begin{abstract}
This paper investigated the analyses of removal of Methylene Blue (MB) and Brilliant Green (BG) dyes from aqueous solutions by adsorption on activated carbon prepared by chemical activation of coconut shell, eucalyptus tree, corn cob and flamboyant pod. It was found that the carbon pores increased after carbonization and activation processes. The maximum percentage MB removal was obtained as $95.0 \%$ for coconut shell, $93.2 \%$ for eucalyptus tree, 99.9\% for corn cob, and $99.7 \%$ for flamboyant pod. Also, the maximum percentage BG removal was obtained as $97.0 \%$ for coconut shell, $98.2 \%$ for eucalyptus tree, $99.6 \%$ for corn cob, and $99.6 \%$ for flamboyant pod. The adsorption isotherms of the adsorption process were studied, and Freundlich model showed the best fit with the equilibrium data. To optimize the operating conditions, the effects of contact time, adsorbent dosage, and $\mathrm{pH}$ were investigated by two levels of factorial experimental design method and adsorbent dosage was found as the most significant factor.
\end{abstract}

\section{Keywords}

Adsorption, Activated Carbons, Acid Activation, Brilliant Green, Two-Level Factorial Design

\section{Introduction}

The release of dyes into wastewater from textile, cosmetic, paper and coloring industries poses serious environmental problems [1]. Dye availability in water, even if it is just small in quantity is unwanted and highly visible. Color prevents the proper entrance of sunlight into water bodies; it also retard photosynthesis; hinder the growth of aquatic biota and affect the solubility of gases within the 
water bodies. Dyes role in connection with several lungs, skin and many other respiratory problems have been reported globally [2]. Direct release of dyes containing wastewater into municipal environment can cause the production of poisonous carcinogenic products. The highest degrees of toxicity were discovered in direct and raw dyes [3]. Therefore, before wastewater is released into municipal environment, it is very important to reduce dye amount or concentration present in it. The commonly applied methods of treating wastewater are coagulation and flocculation, electrochemical treatment, liquid-liquid extraction, chemical oxidation and adsorption. Many methods have recently been used to remove both $\mathrm{MB}$ and $\mathrm{BG}$ from industrial effluents. Among these methods, adsorption is the most effective way for the removal of organic compounds from solution in term of its low cost of operation, ease of design, sensitivity to poisonous materials and simplicity of operation [1]. But its use is limited because of high cost and associated problems of regeneration, and this problem has initiated a constant and continuous search for cheaper alternatives. The search for the removal of organic pollutants using alternative low cost adsorbents is now on the rise by many researchers [4]. Wide varieties of high carbon content materials such as wood, coal, peat; nutshells, sawdust, bones, husk, petroleum coke and others have been utilized to produce activated carbon of varying efficiencies [5]. These materials, usually in irregular and bulky shapes, are always adjusted to exhibit the desired final shapes, roughness and hardness. Generally, the production of activated carbon involves pyrolysis or carbonization and activation as the two main production processes [6]. Numerous carbonaceous materials, particularly, those of agricultural base, are being investigated to possess potential as activated carbon. The suitable ones have minimum amount of organic material and a long storage life. Similarly they consist of hard structure to maintain their properties under usage conditions. They can be obtained at a low cost. Some of the materials that meet the above conditions have been used, in past works, to produce activated carbons which were subsequently used for the treatment of wastewater and adsorption of hazardous gases. Agricultural by-products like rice straw, soybean hull, sugarcane bagasse, peanut shell, pecan shell and walnut shells were used by V. Ponnusami et al., (2007) to produce Granulated Activated Carbons (GACs). The choice of a particular material for the production of effective adsorbent (activated carbon) is based on low cost, high carbon and low inorganic content. Agricultural materials have attracted the interest of researchers for the production of adsorbents because of their availability in large amount and at a low cost [7]. The selected materials employed in this study were coconut shell, corn cob, flamboyant pod and eucalyptus tree. Use of agricultural by-product for the production of activated carbon is primarily for economic and ecological advantages [8]. Commercial activated carbon used in surface and wastewater treatment is largely derived from coal. The advantages of coal-based carbons can be seen in their ability to remove toxic organic compounds from industrial and municipal wastewater as well as potable water. Another significant application of coal-based carbons is decolorization. The feedstock for these car- 
bons, usually bituminous coal, is a non-renewable resource. The long-term availability of coal and its long-term environmental impact coupled with its potentially increasing cost has prompted researchers to consider renewable resources such as agricultural by-products as an alternative. Many efforts have been made to use low cost agro-waste materials in substitute for commercial activated carbon [9]. Some agro-waste materials studied for their capacity to remove dyes from aqueous solutions are coir pith, pine sawdust, tamarind fruit shell, bagasse, rice husk, orange peel, palm kernel shell, cashew nut shell, wallnut shell [10]. The present investigation is an attempt to remove Methylene Blue (MB) and Brilliant Green (BG) from synthetic wastewater by adsorption process using a low cost activated carbon prepared from agricultural wastes as an adsorbent. The coconut shell and corn cob are considered as agricultural wastes, therefore using them as raw materials for production of activated carbon is much more economical than the coal based activated carbon. In this study, the carbon adsorption method will be investigated for its efficiency in color removal from water bodies.

\section{Materials and Methods}

\subsection{Carbonization}

$1 \mathrm{~kg}$ of each agricultural waste material (coconut shell, eucalyptus tree, corn cob and flamboyant pod) was charged into electric muffle furnace, which was then heated in the absence of oxygen at a temperature of $300^{\circ} \mathrm{C}-600^{\circ} \mathrm{C}$ for one hour. The resulting charred materials were collected and cooled at room temperature.

\subsection{Activation}

Samples of all the carbonized material were weighed on electric weigh machine, soaked in one mole of phosphoric acid $\left(\mathrm{H}_{3} \mathrm{PO}_{4}\right) 63 \%$ concentrated solution for 24 hours. The materials were then removed from the soaking after the 24 hours lapsed, and then washed with distilled water until leachable impurities due to free acid and adherent powder were removed and the $\mathrm{pH}$ of the water was 7. Finally, the samples were drained and dried in an oven at $80^{\circ} \mathrm{C}$ for another 12 hours.

\subsection{Preparation of Dye Solution}

The accurately weighted (0.003 gram) of each $\mathrm{MB}$ and $\mathrm{BG}$ were dissolved in a distilled water to prepare dye mixture stock solution. $1000 \mathrm{mg} / \mathrm{L}$ stock solution of synthetic wastewater was prepared using blue and green dyes and from which other desired concentrations were obtained. The $\mathrm{pH}$ of the working solutions was adjusted to the required values of 4 and 11 by adding $0.1 \mathrm{M} \mathrm{HCl}$.

\subsection{Batch Adsorption Studies}

For batch studies, the aim was to increase the dye adsorption efficiency during purification operation. To systematically explore process options, a full-factorial two-level design on the key factors was set up. Only three factors affecting dye 
adsorption efficiency were studied in this work, including contact time, dosage and $\mathrm{pH}$. The symbols of minus (-) and plus (+) were used to designate low and high levels, respectively. Batch adsorption experiment was carried out in a set of 250 conical flasks containing $80 \mathrm{~mL}$ dye solution. The experiments were run according to $2^{3}$ factorial design template designed for operation. The shaker speed was kept constant throughout the experiments run. After the completion of each experiment, the conical flask was withdrawn from the shaker at the pre-determined time interval and the supernatant solution was separated by filtration using whatman filter paper. Standard calibration curve was developed at wavelength of $664 \mathrm{~nm} \mathrm{MB}$ dye and 629 for BG dye. The final concentration was then analysed for absorbance by using Ultra-violet spectrophotometer with a blank solution as control. The percentage colour removal efficiency was calculated using:

$$
\text { \%Removal }=\frac{C_{i}-C_{f}}{C_{i}} \times 100
$$

where, $C_{i}(\mathrm{mg} / \mathrm{L})$ is the initial dye concentration, $C_{f}(\mathrm{mg} / \mathrm{L})$ final colour concentration.

The uptake of dye at equilibrium time was calculated from

$$
q_{e}=\frac{\left(C_{o}-C_{e}\right) V}{w}
$$

where $q_{e}$ is the amount of adsorbed dye in $\mathrm{mg} / \mathrm{g} . C_{o}$ and $C_{e}$ are the initial and equilibrium dye concentration in $\mathrm{mg} / \mathrm{L}, V$ is the volume of the aqueous solution in $\mathrm{ml}$ and $w$ is the mass of the adsorbent in g. Langmuir and Freundlich adsorption isotherm models were used to explain the sorption data obtained in this work.

\section{Results and Discussion}

\subsection{Carbons Adsorption Comparison}

The results as shown in Figure 1 and Figure 2 compare the dye adsorption during

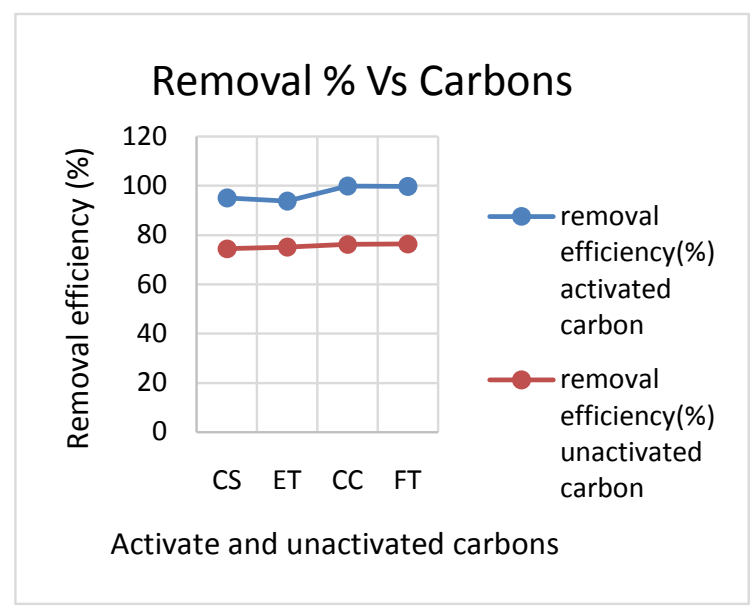

Figure 1. MB removal efficiency. 
batch experiments using activated and un-activated carbon. The graphs clearly show that activated carbon is better during adsorption process than un-activated carbon. It also shows that, all the activated carbons used during the experiments adsorbed dye from the dye solution more than all the un-activated carbons used for the experiments [11]. The graphs were plotted using the dye highest percentage removal in each experimental run for both activated and un-activated carbon. All the activated carbons used in the experiments have adsorption removal efficiency above $94.9 \%$ to $99.9 \%$ for both MB and BG. All the un-activated carbons have their highest between $72.5 \%$ to $76.3 \%$. All the carbons flamboyant pod were activated using the same conditions of carbonization of $500^{\circ} \mathrm{C}$ for 1 hour, and activation was done with 1 mole of $63 \%$ phosphoric acid and soaked for 24 hours.

\subsection{Isotherm Models}

Table 1 and Table 2 shows Freundlich and Langmuir coefficients and regression

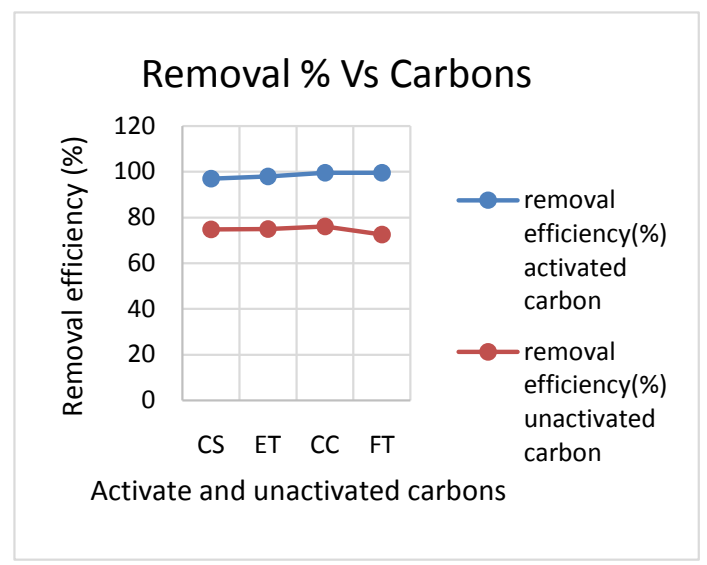

Figure 2. BG removal efficiency.

Table 1. Freundlich data.

\begin{tabular}{cccc}
\hline & \multicolumn{3}{c}{ Freundlich } \\
\hline Adsorbents & $1 / \mathrm{n}$ & $\mathrm{K}_{\mathrm{f}}(\mathrm{mg} / \mathrm{g})$ & $\mathrm{R}^{2}$ \\
\hline Coconut shell & 0.417 & 2.13 & 0.9970 \\
Eucalyptus tree & 0.385 & 2.15 & 0.9934 \\
Corn cob & 0.388 & 2.10 & 0.9948 \\
Flamboyant pod & 0.444 & 2.10 & 0.9966 \\
\hline
\end{tabular}

Table 2. Langmuir data.

\begin{tabular}{ccccc}
\hline & \multicolumn{5}{c}{ Langmuir } \\
\hline Adsorbents & $\mathrm{b}(\mathrm{L} / \mathrm{mg})$ & $\mathrm{a}(\mathrm{mg} / \mathrm{g})$ & $\mathrm{R}^{2}$ & $\mathrm{R}_{\mathrm{L}}$ \\
\hline Coconut shell & 0.0013 & 0.008 & 0.9726 & 0.961 \\
Eucalyptus tree & 0.0015 & 0.007 & 0.9297 & 0.955 \\
Corn cob & 0.0014 & 0.008 & 0.9674 & 0.958 \\
Flamboyant pod & 0.0014 & 0.009 & 0.9728 & 0.958 \\
\hline
\end{tabular}


correlation coefficients for adsorption of $\mathrm{MB}$ and $\mathrm{BG}$ dyes onto coconut shell carbon, eucalyptus carbon, corn cob carbon and flamboyant pod carbon at ambient temperature.

The initial dye concentration varied as 5, 10, 15, 20 and $25 \mathrm{mg} / \mathrm{L}$, and four different adsorbent dosages of each $5 \mathrm{~g}$ was used for comparison. All constants and $\mathrm{R}^{2}$ values obtained for both models are summarized in Table 1 and Table 2. According to Table 1 and Table 2, the highest correlation coefficient ( $\mathrm{R}^{2}$ values) were obtained from Freundlich equation; thus, the Freundlich model displayed better fit to the adsorption data than Langmuir model [12]. This result indicated that the surface of the produced carbons for adsorption of $M B$ and $B G$ were made up of heterogeneous adsorption patches [13].

\subsection{Two-Level Factorial Design of Experiments}

Dye removal by an adsorbent in a batch experiments usually depends on many factors. These factors include contact time, adsorbate dosage, $\mathrm{pH}$, and so forth. To systematically explore process options, a full-factorial two-level design on the key factors was set up as shown in Table 3.

Only three factors affecting dye adsorption efficiency were studied in this work, including contact time, adsorbent dosage and $\mathrm{pH}$. The first factor, contact time is numerical because it can be adjusted to any level. Also, the second factor, dosage and the third factor, $\mathrm{pH}$ are also numerical. None of the factors used in this design is categorical, that is factor that cannot be adjusted. The experiments for two-level factorial design were carried out in a set of $250 \mathrm{ml}$ conical flasks containing $80 \mathrm{ml} \mathrm{MB}$ and $\mathrm{BG}$ dyes solution of known $\mathrm{pH}$, adsorbent dose and agitated for predetermined contact time. After thirty and ninety hours of agitation, the suspensions were filtered and dye concentrations in the supernatant solutions were measured using a UV-Vis spectrophotometer. The experimental design results were analysed using DESIGN EXPERT software to estimate the statistical parameters as well as effects, such as half-normal probability of the standardized effects, Pareto, interaction and main effects plots. $2^{3}$ two-level factorial design with 8 runs experimentation for MB and BG removal was studied, and amatrix was developed according to their low and high levels, represented by -1 and +1 , respectively. The coded values of variables with the responses (\% removal efficiency) were illustrated in Table 4.

The interactions between independent variables were determined with ANOVA and the main effects of MB and BG adsorption were identified based on the $\mathrm{P}$ value with $>95 \%$ of confidence level.

The codified equation below was used to explain the $2^{3}$ factorial designs of $\mathrm{MB}$ and BG removal by four different activated carbons:

Table 3. Test factors for dye adsorption.

\begin{tabular}{ccc}
\hline Factors & Low level (-) & High level $(+)$ \\
\hline Contact time (mins) & 30 & 90 \\
Adsorbent Dosage (g) & 2 & 5 \\
pH. & 4 & 11 \\
\hline
\end{tabular}




$$
Y=\beta_{0}+\beta_{1} \mathrm{~A}+\beta_{2} \mathrm{~B}+\beta_{3} \mathrm{C}+\beta_{4} \mathrm{AB}+\beta_{5} \mathrm{AC}+\beta_{6} \mathrm{BC}+\beta_{7} \mathrm{ABC}
$$

where $Y$ is the predicted response, $\beta_{0}$ is the intercept, $\beta_{i}$ is the regression coefficient related to the interactions and the main factors effects $\mathrm{A}$ is the contact time (mins), B is the adsorbent dosage ( $\mathrm{g}$ ), and $\mathrm{C}$ is the $\mathrm{pH}$. The interaction and main effects, regression coefficients, coefficients of the model, standard deviation of each coefficient, standard errors, and $\mathrm{T}$ and $\mathrm{P}$ values were also done.

From Table 5 and Table 6, when the factor effect is negative, removal efficiency decreases as the factor is changed from low to high levels (as seen from dosage and $\mathrm{pH}$ ). In contrast, if the effects are positive, removal efficiency increases for high level of the same factor (as seen from adsorbent dosage and $\mathrm{pH}$ ). When the factor effect is negative, removal efficiency decreases as the factor is changed from low to high levels (as seen from $\mathrm{pH}$ and contact time). Furthermore, the fit models, submitted square correlation coefficient $\left(\mathrm{R}^{2}\right)$ of 0.9992 for $\mathrm{MB}$ and 0.9939 for $\mathrm{BG}$, were in good agreement with the statistical model. The factors $\mathrm{A}, \mathrm{B}$ and $\mathrm{C}$ are the frequently called a main effect as it refers to the primary factor of interest in the experiment and factors $\mathrm{AB}, \mathrm{AC}$ and $\mathrm{BC}$ are interactions effects. In this work, factors $\mathrm{A}, \mathrm{B}, \mathrm{C} \mathrm{AC}$, and $\mathrm{BC}$ are all significant effects. The $A B$ and $A B C$ effect were insignificant, when it was compared with other

Table 4. Design matrix for MB and BG.

\begin{tabular}{cccccc}
\hline Runs & A & B & C & MB adsorption & BG adsorption \\
\hline 1 & - & - & - & 75 & 75 \\
2 & + & - & - & 85 & 83 \\
3 & - & + & - & 90 & 90 \\
4 & + & + & - & 92 & 94 \\
5 & - & - & + & 82 & 83 \\
6 & + & - & + & 80 & 81 \\
7 & - & + & + & 95 & 97 \\
8 & + & + & + & 80 & 79 \\
\hline
\end{tabular}

Table 5. Interaction of dosage versus $\mathrm{pH}$.

\begin{tabular}{cccc}
\hline Standard & Dosage & $\mathrm{pH}$ & MG average Adsorption \\
\hline 1,2 & - & - & 80.0 \\
3,4 & + & - & 85.0 \\
5,6 & - & + & 81.0 \\
7,8 & + & + & 93.5 \\
\hline
\end{tabular}

Table 6. Interaction of dosage versus $\mathrm{pH}$.

\begin{tabular}{|c|c|c|c|}
\hline Standard & Dosage & $\mathrm{pH}$ & BG average Adsorption \\
\hline 1,2 & - & - & 79.0 \\
\hline 3,4 & + & - & 84.5 \\
\hline 5,6 & - & + & 82.0 \\
\hline 7,8 & + & + & 95.5 \\
\hline
\end{tabular}


effects. Thus the $A B$ and $A B C$ effects were neglected and did not included in the model equation. Then, model equation, related to the level of parameters and removal efficiency, was obtained by substituting the regression coefficients in for both MB and BG:

MB adsorption model $=84.88+3.12 \mathrm{~A}+4.38 \mathrm{~B}+2.37 \mathrm{C}-1.88 \mathrm{AC}+1.88 \mathrm{BC}$

$\mathrm{BG}$ adsorption model $=85.25+3.00 \mathrm{~A}+4.75 \mathrm{~B}+3.50 \mathrm{C}-1.75 \mathrm{AC}+2.00 \mathrm{BC}$

Equations (4) and (5) indicated that two-variable interactions were significant. Proof of positive (BC) and negative (AC) interactions was quite strong, thus, could not be ignored from the model. Although the main effects gave a clear idea, the interaction between those two parameters would favor a better statement of the process.

The interactions between independent factors were determined with analysis of variance (ANOVA) and the main effects of dye adsorption were identified based on the P value with $>95 \%$ of confidence level are presented in ANOVA Table 7 and Table 8 . The tables presented the possible positive and negative two-variable interactions among the variables $\mathrm{A}, \mathrm{B}$, and $\mathrm{C}$ for the removal efficiency (\%).

Table 7. Statistical parameters and ANOVA for removal efficiency (\%).

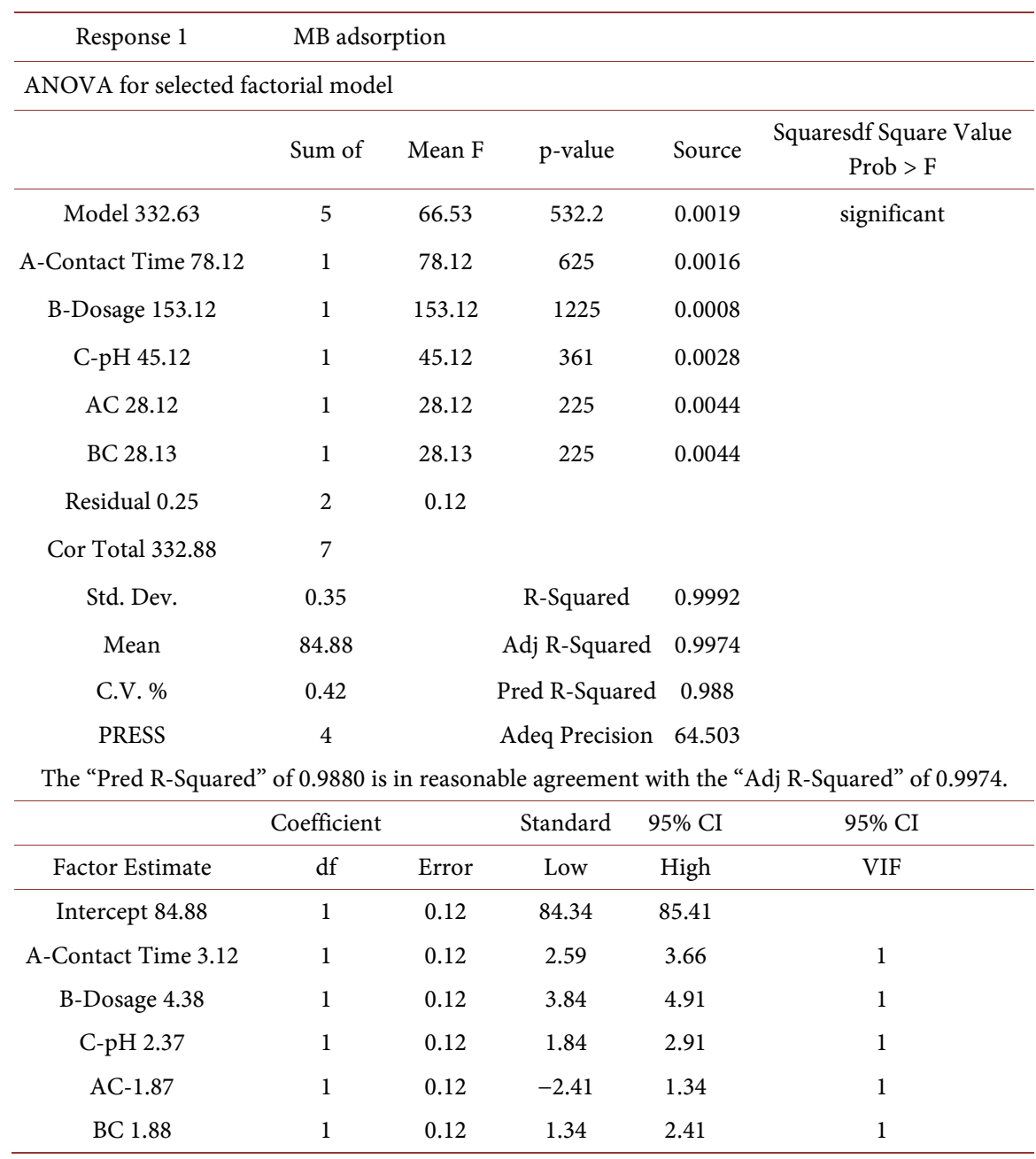


Table 8. Statistical parameters and ANOVA for removal efficiency (\%).

\begin{tabular}{|c|c|c|c|c|c|}
\hline Response 02 & \multicolumn{5}{|c|}{ BG adsorption } \\
\hline \multicolumn{6}{|c|}{ ANOVA for selected factorial model } \\
\hline Source & Sum of & Mean & $\mathrm{F}$ & $\mathrm{p}$-value & Square Value Prob $>$ F \\
\hline Model 407.00 & 5 & 81.4 & 65.12 & 0.0152 & significant \\
\hline A-Contact Time 72.00 & 1 & 72 & 57.6 & 0.0169 & \\
\hline B-Dosage 180.50 & 1 & 180.5 & 144.4 & 0.0069 & \\
\hline C-pH 98.00 & 1 & 98 & 78.4 & 0.0125 & \\
\hline AC 24.50 & 1 & 24.5 & 19.6 & 0.0474 & \\
\hline BC 32.00 & 1 & 32 & 25.6 & 0.0369 & \\
\hline Residual 2.50 & 2 & 1.25 & & & \\
\hline Cor Total 409.50 & 7 & & & & \\
\hline Std. Dev. & 1.12 & & R-Squared & 0.9939 & \\
\hline Mean 85.25 & & & dj R-Squared & 0.9786 & \\
\hline C.V. $\%$ & 1.31 & & red R-Squared & 0.9023 & \\
\hline PRESS & 40 & & deq Precision & 23.238 & \\
\hline \multicolumn{6}{|c|}{ The "Pred R-Squared" of 0.9023 is in reasonable agreement with the "Adj R-Squared" of 0.9786.} \\
\hline & \multicolumn{2}{|c|}{ Coefficient } & Standard & $95 \% \mathrm{CI}$ & $95 \% \mathrm{CI}$ \\
\hline Factor Estimate & $\mathrm{df}$ & Error & Low & High & VIF \\
\hline Intercept 85.25 & 1 & 0.4 & 83.55 & 86.95 & \\
\hline A-Contact Time 3.00 & 1 & 0.4 & 1.3 & 4.7 & 1 \\
\hline B-Dosage 4.75 & 1 & 0.4 & 3.05 & 6.45 & 1 \\
\hline C-pH 3.50 & 1 & 0.4 & 1.8 & 5.2 & 1 \\
\hline AC- 1.75 & 1 & 0.4 & -3.45 & -0.049 & 1 \\
\hline BC 2.00 & 1 & 0.4 & 0.3 & 3.7 & 1 \\
\hline
\end{tabular}

It was observed that the effect of $\mathrm{pH}$ was more noticeable when the adsorbent dosage was high but at lower adsorbent dosage, effect of $\mathrm{pH}$ was not so high. On the contrary, $\mathrm{pH}$ effect and adsorbent dosage effect were high at higher contact time. The interaction effects are easily estimated and tested by using the ANOVA as shown in Figure 3. The ANOVA results of MB and BG were shown in Table 7 and Table 8 above. The sum of the squares used to estimate factors affect and Fisher's $F$ ratios (defined as the ratio of mean square effect and the mean square error) and $\mathrm{P}$ values (defined as the level of significance leading to the rejection of the null hypothesis) were also represented. Relative importance of the individual and interaction effects was given by the Pareto chart of the standardized effects in Figure 4. In order to identify whether the calculated effects were significantly different from zero, Student's t-test was performed and horizontal columns in Pareto chart showed these values for each effect. The normal probability plot of the standardized effects with $\mathrm{P}=0.05$ to evaluate the significance of each factor and its interactions on removal efficiency (\%) are presented in Figure 5. Half-Normal probability plot could be separated into two regions, the region on the right side has all the effects that were significant. For a 
Design-Expert $®$ Softw are

MB adsorption

- C- 4.000

$\Delta \mathrm{C}+11.000$

$\mathrm{X} 1=\mathrm{B}:$ Dosage

$\mathrm{X} 2=\mathrm{C}: \mathrm{pH}$

Actual Factor

A: Contact Time $=60.00$

Design-Expert $\circledast$ Softw are

BG adsorption

- C- 4.000

$\Delta \mathrm{C}+11.000$

$\mathrm{X} 1=\mathrm{B}$ : Dosage

$\mathrm{X} 2=\mathrm{C}: \mathrm{pH}$

Actual Factor

A: Contact Time $=60.00$

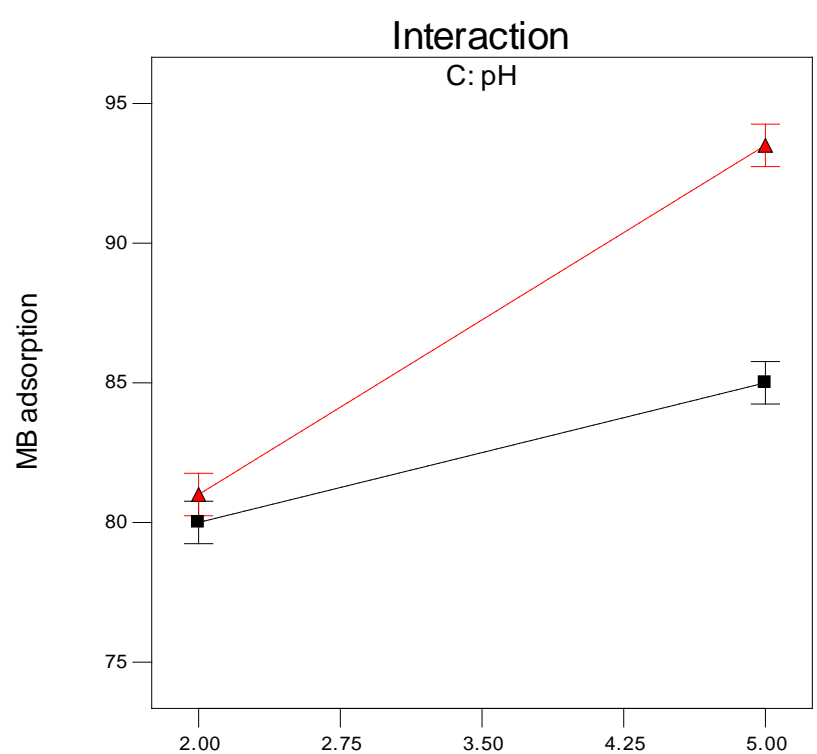

B: Dosage

Interaction

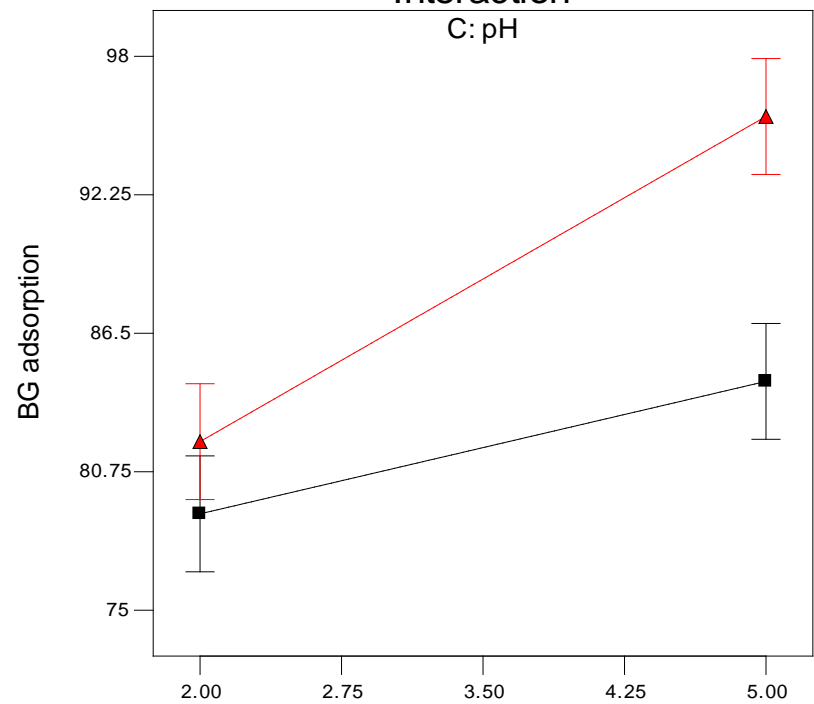

B: Dosage

Figure 3. Interaction graph of dosage versus $\mathrm{pH}$ for MG and BG.

95\% confidence level and seven degrees of freedom, Bonferroni limit was 11.7687 and t-value limit was 4.30265 for MB and BG adsorption. The minimum statistically significant effect magnitude for $95 \%$ confidence level is represented by the vertical line in the chart. Five values higher than $4.30265(\mathrm{P}=0.05)$ were located at left of the dash line and were significant. It can be concluded that the adsorbent dosage was the strongest effect of the overall adsorption procedure for both MB and BG SCAC. The first (strongest effect), second, third, fourth and fifth important factor to the overall optimization of the batch adsorption process were arranged in sequential order in Pareto chart for both MB and BG. Factor B, $A, C, A C$ and $B C$ show the order of significant of each effect on $M B$ adsorption 

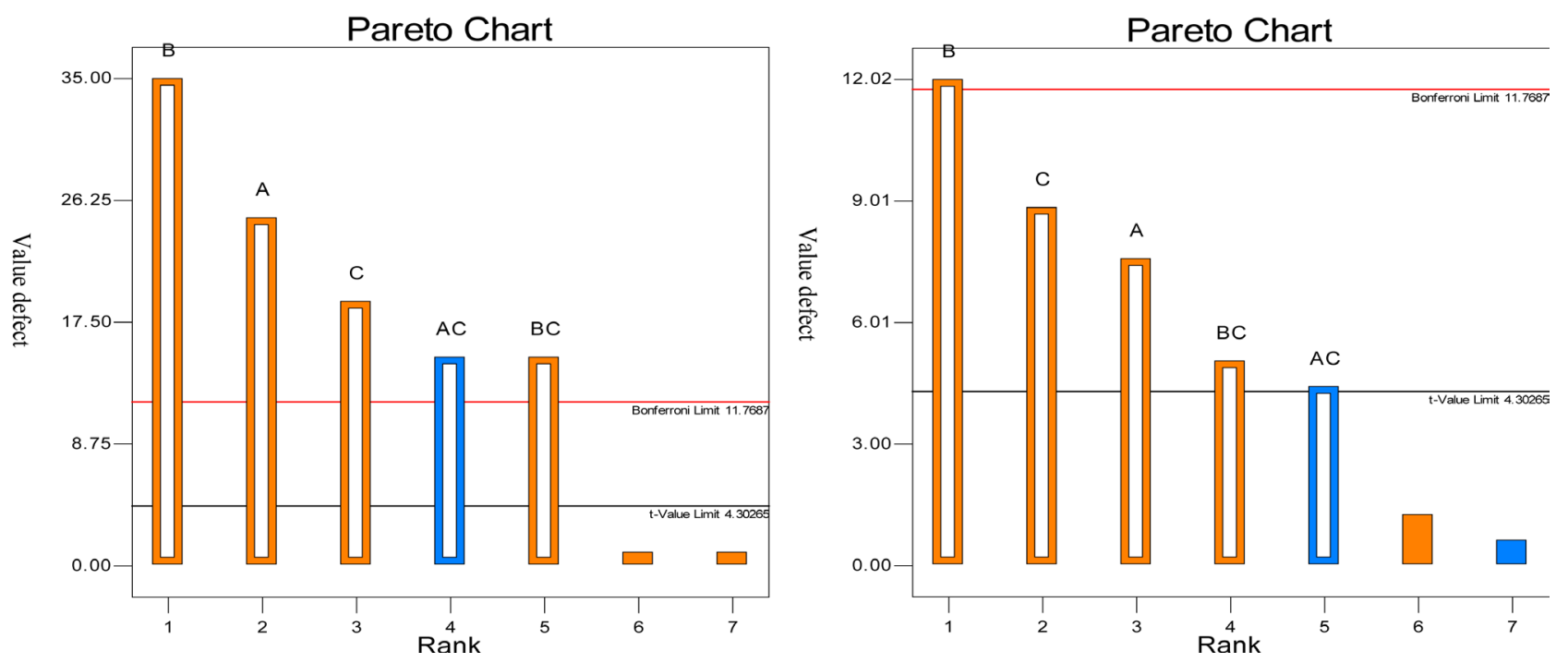

Figure 4. Pareto chart of effects for MB and BG adsorption.
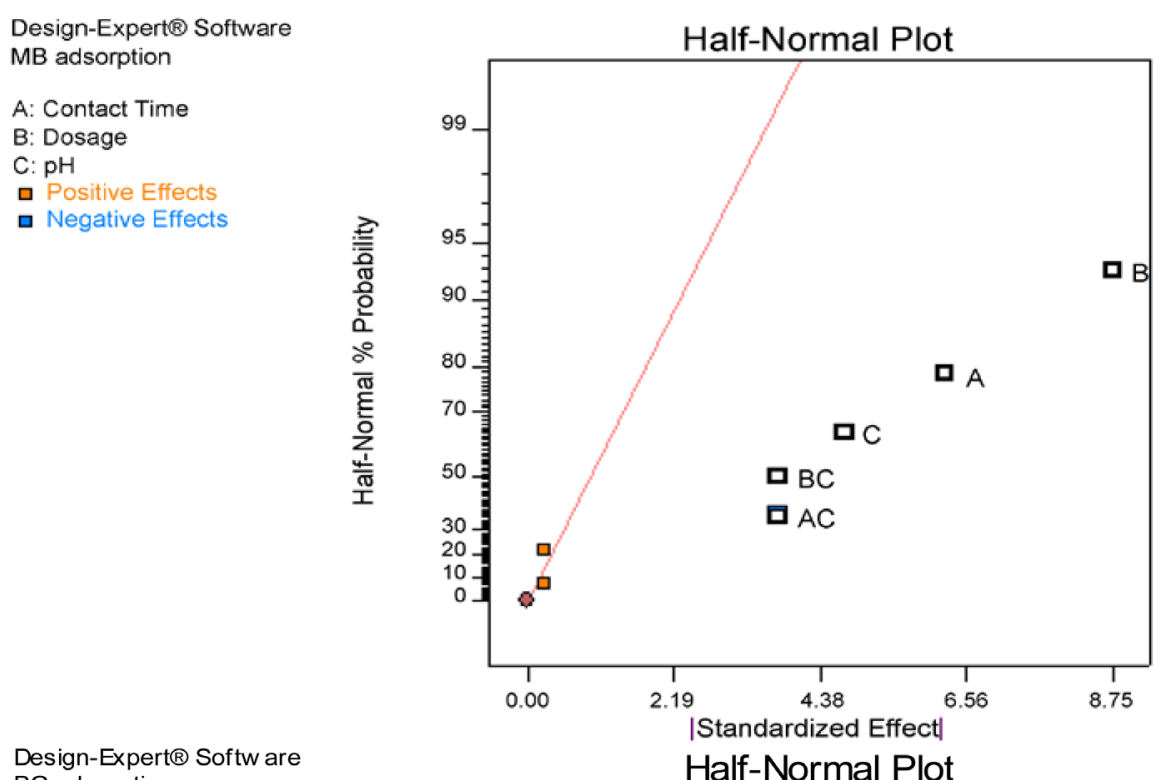

Design-Expert $\circledast$ Softw are BG adsorption

Half-Normal Plot
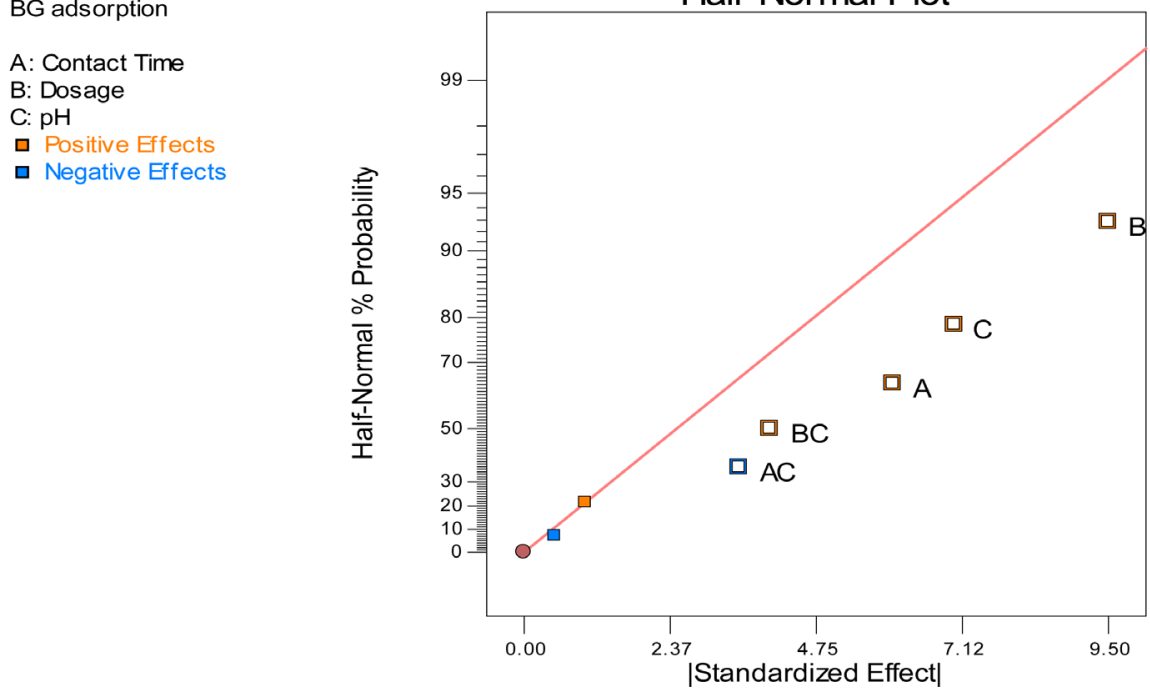

Figure 5. Half-normal probability plot of the standardized effects for MB and BG at $P=0.05$. 
process. Similarly, factor B, C, A, BC and AC show the order of significance of each effect on BG adsorption process. The coefficient of $A C$ interaction for both $\mathrm{MB}$ and $\mathrm{BG}$ adsorption had the negative value; thus, a decrease in contact time of the solution with a deduction of the $\mathrm{pH}$ caused an increase in removal efficiency (\%). This antagonistic effect would not be distinguished in the univariate optimization of the dye removal process.

\section{Conclusions}

Carbon produced by chemical activation of carbonized coconut shell, eucalyptus tree, corn cob and flamboyant pod with an activation agent $63 \% \mathrm{H}_{3} \mathrm{PO}_{4}$ were all capable of removing Methylene Blue and Brilliant Green dye molecules from aqueous solutions. The adsorption was favoured at Basic medium with $\mathrm{pH}$ value 11 and adsorption efficiency (\%) was also found to increase with the increase in adsorbent dosage and contact time.

The equilibrium data were in good agreement with the Freundlich model. Additionally, the influence of $\mathrm{pH}$ ( 4 and 11), adsorbent dosage (2 $\mathrm{g}$ and $5 \mathrm{~g}$ ) and contact time (30 mins and 90 mins) on removal efficiency (\%) was designed by using $2^{3}$ two level factorial design. It was examined by using analysis of variance (ANOVA), t-test, and Bonferroni - test. According to Pareto Chart, half-normal, normal probability plot, main effects, interaction plots in variance analysis, the most significant factors on removal efficiency (\%) were found to be adsorbent dosage $(\mathrm{B})$, contact time $(\mathrm{A}), \mathrm{pH}(\mathrm{C})$, the interaction between adsorbent dosage and $\mathrm{pH}(\mathrm{BC})$ and interaction between contact time and $\mathrm{pH}(\mathrm{AC})$, respectively.

Due to the obtained results, black carbons which are produced from chemical activation of carbonized coconut shell, eucalyptus tree, corn cob and flamboyant pod could be employed as an effective and low-cost adsorbent. Therefore, these successful adsorbents could be considered as an alternative to commercial activated carbons for the removal of reactive Methylene blue and brilliant green from aqueous solutions.

\section{References}

[1] ElQada, E.N., Allen, S.J. and Walker, G.M. (2008) Adsorption of Basic Dyes from Aqueous Solution onto Activated Carbons. Chemical Engineering Journal, 135, 174-184. https://doi.org/10.1016/j.cej.2007.02.023

[2] Cooper, P. (1993) Removing Colour from Dyehouse Wastewaters-A Critical Review of technology Available. Journal of the Society of Dyers and Colourists, 109, 97-100.

[3] Jadhav, S.B., Phugare, S.S., Patil, P.S. and Jadhav, J.P. (2011) Biochemical Degradation Pathway of Textile Dye Remazol Red and Subsequent Toxicological Evaluation by Cytotoxicity, Genotoxicity and Oxidative Stress Studies. International Biodeterioration and Biodegradation, 65, 733-743. https://doi.org/10.1016/j.ibiod.2011.04.003

[4] Gupta, V.K., Gupta, B., Rastogi, A., Agarwal, S. and Nayak, A. (2011) A Comparative Investigation on Adsorption Performances of Mesoporous Activated Carbon Prepared from Waste Rubber Tire and Activated Carbon for a Hazardous Azo 
Dye-Acid Blue 113. Journal of Hazardous Materials, 186, 891-901.

https://doi.org/10.1016/j.jhazmat.2010.11.091

[5] Bonnamy, S. (1999) Carbonization of Various Precursors. Effect of Heating Rate. Part II. Transmission Electron Microscopy and Physicochemical Studies. Carbon, 37, 1707-1724. https://doi.org/10.1016/S0008-6223(99)00044-5

[6] Bourrat, X. (1997) Structure in Carbons and Carbon Artefacts. In: Marsh, H. and Rodriguez-Reinoso, F., Eds., Sciences of Carbon Materials, Universidad de Alicante, Secretariado de Publications, Spain, 1-97.

[7] Marsh, H., Heintz, E.A. and Rodriguez-Reinoso, F., Eds. (1997) Introduction to Carbon Technologies. Universidad de Alicante, Secretariado de Publications, Spain, 669.

[8] Marsh, H. and Rodriguez-Reinoso, F., Eds. (2000) Science of Carbon Materials. Universidad de Alicante, Secretariado de Publications, Spain, 673.

[9] Marsh, H. (2001) Carbon Mesophase. In: Buschew, K.H, Cahn, J., Robert, W., Flemings Merten, C., IIscher, B., Kramer Edward, J., Subhash, M. and Patrick, V., Eds., Encyclopedia of Materials. Science and Technology, Elsevier Science Ltd., Amsterdam, 926-932. https://doi.org/10.1016/B0-08-043152-6/00177-7

[10] Mattson, J.S. and Mark, H.B. (1971) Activated Carbon. Marcel Dekker Inc., New York, 237.

[11] McGuire, M.J. and Suffet, I.H., Eds. (1980) Activated Carbon Adsorption of Organics from the Aqueous Phase, Vol. 1. Ann Arbor Science Publishers Inc., Michigan, 508.

[12] McGuire, M.J. and Suffet, I.H., Eds. (1980) Activated Carbon Adsorption of Organics from the Aqueous Phase, Vol. 2. Ann Arbor Science Publishers Inc., Michigan, 589.

[13] McGuire, M.J. and Suffet, I.H., Eds. (1983) Treatment of Water by Granular Activated Carbon, Advances in Chemistry Series, 202. American Chemical Society, Washington, 599. https://doi.org/10.1021/ba-1983-0202

\section{Scientific Research Publishing}

Submit or recommend next manuscript to SCIRP and we will provide best service for you:

Accepting pre-submission inquiries through Email, Facebook, LinkedIn, Twitter, etc. A wide selection of journals (inclusive of 9 subjects, more than 200 journals)

Providing 24-hour high-quality service

User-friendly online submission system

Fair and swift peer-review system

Efficient typesetting and proofreading procedure

Display of the result of downloads and visits, as well as the number of cited articles

Maximum dissemination of your research work

Submit your manuscript at: http://papersubmission.scirp.org/

Or contact jeas@scirp.org 